\title{
Concerning the principles of development of mineral resources in the polar zone of Russia by small enterprises
}

\author{
Vladimir Gavrilov ${ }^{*}$, Yevgeniy Khoyutanov ${ }^{1}$ and Natalia Batugina ${ }^{1}$ \\ ${ }^{1}$ Mining Institute of the North, Siberian Branch, Russian Academy of Sciences, Yakutsk, Russia
}

\begin{abstract}
Increasing the efficiency of developing deposits of solid minerals in the polar zone of the northeast of Russia is an objective necessity. Unlike traditional territories, the peculiarities of the region predetermine the use of new approaches and methods in studying the feasibility of developing various deposits, including the widely represented relatively small deposits. Compared to large ones, medium and small mining enterprises operating or created on their basis have fewer opportunities to protect their interests. Their design and actual technical and economic indicators are generally worse than those of more powerful economic entities. The decrease in the scale effect can be achieved in various ways. Reduction of risks in the implementation of investment projects is possible through more thorough study and subsequent additional training, as a rule, complex in structure and heterogeneous in quality deposits involved in operation. A set of basic and private principles of different levels and values has been formed, which should guide small and medium-sized enterprises in the planning, design and development of deposits in the polar zone of Russia. Its use in the preparation and decisionmaking allows at least partially to reduce the impact of complicating and costly production factors. Keywords. Development of deposits, principles, solid minerals, small enterprises, the polar region, geotechnology, decision-making.
\end{abstract}

\section{INTRODUCTION}

Long-term analysis of the theory and practice shows that the extreme combination of natural climatic, mining-geological, technological, logistical and environmental conditions in the polar region of Russia significantly complicates or makes unacceptable by a combination of criteria the main activities related to the effective extraction and processing of mineral wealth. Really, only a small part of the reserves of solid minerals (SM) is processed. Basically, these are deposits of high-value raw materials with short technological chains and low-tonnage output of finished products. The imperfection of many aspects of the subsoil use mechanism in the region leads to irrational approaches to the development of subsoil. A consequence is the full or partial non-fulfillment of projects

* Corresponding author: gvlugorsk@mail.ru 
for the development of many types of SM widely migrating from one program document to another over years, the inability to achieve the planned indicators, the low demand for georesources, the lack of research to identify and explain the reasons for such a situation.

In the polar zone of Russia, various SM deposits are being developed or planned for development. They can be large (iron or apatite ores in Murmansk region, precious metal and polymetallic ores in Norilsk industrial hub, gold ore in Chukotka), developed by large enterprises over decades; and there may be middle and small deposits, for example, placers, which are worked out by small artels, including during only a few seasons.

The first of these, as a rule, have multiple opportunities to defend their interests. The latter have techno-economic indicators are generally much worse than more powerful business entities. The possibilities of applying modern types of equipment and technologies, methods of organization and management in accordance with modern trends due to a number of reasons, primarily financial, are more limited. Without special support measures, for example, using public-private partnerships [1, 2], their normal functioning under extreme polar conditions is greatly complicated. Limited in comparison with large enterprises, the opportunities for small and medium-sized enterprises require the use of a synthesis of general and private approaches to identifying reserves for effective development of subsoil in the region. In this case, universal approaches should be based on general knowledge and the patterns of their production [3, 4, etc.], and individual - apply taking into account the specific specificity of each individual deposit based not only on clarifying general knowledge, but also by obtaining new, resulting from the features of the fields and the supply chains that they form.

This combination allows, when implementing investment projects in the mineral and raw materials sector, to achieve a level of profitability acceptable for relatively normal operation of enterprises, taking into account the interests of investors, federal, regional and local government authorities. Two main things should be remembered. First: there is a stable, often unjustified, view of the uniqueness and richness of the region's mineral and raw materials base (MRB) and constantly announced hope for high and stable demand in the country and the world for its SM. Second: the current state and prospects for the development of the territory are associated primarily with the raw material sector and are actually non-alternative. For the region, more economical types of production cannot be offered by science and practice yet. The efficiency of a job in the mining sector is 3-5 or more times higher than in other sectors.

Adaptation of common solutions for real mining and geological conditions, properties of mined minerals and formed chains of creation of value added allows one to more accurately consider and evaluate the feasibility of involving profitable SM deposits in the region. The foregoing allows one to state that the solution of interrelated and complementary tasks on the analysis of existing principles for the development of mineral resources and on the synthesis of a complex of those that can be rationally used to increase the efficiency of small-scale mining enterprises is urgent. There is a need to formulate the necessary and sufficient conditions for real involvement of regional MRB in effective and environmentally safe operation.

\section{THEORY}

Reduction of risks in the implementation of investment projects is possible through more thorough study and subsequent additional preparation for operation of deposits, as a rule, complex in structure and heterogeneous in quality. At the same time, following a unified approach to business taxation, regardless of where it is based in Moscow or the Arctic Circle, is an erroneous understanding of the principle of equal competitiveness or "the conscious displacement of the remnants of economic presence from the pioneer 
development regions" [5]. It is necessary to revise the approaches used to select geotechnologies and related processes. Priority should be given to those of them that allow for the most complete consideration of local climatic, mining and geological and cryological features of deposits that are able to react quickly to changes in the conditions for the development of their individual sites.

The scientific literature covers a wide range of issues related to the Russian polar zone $[6,7]$ and the world [8-10], the ecological efficiency of technologies for the development of SM deposits [11], the development of individual industries in the regions $[1,12]$, the transport and logistics infrastructure [13], the combination of geotechnologies for a sustainable development of subsoil [14], geotechnological preparation of deposits with small reserves [15], the association of small and medium-sized gold mining enterprises to increase the efficiency of their operation [16], etc. However, the copying of research results and best practices of the mining sector to the conditions for the development of specific deposits or their groups in the polar regions of Russia is in most cases difficult or has a short-term positive impact. Standard approaches, as a rule, do not provide additional competitive opportunities, because have already been widely used in other regions with more comfortable conditions for solving similar problems.

Despite the attempts made, the whole complex of constantly replenishing specific features of the development of remote, inaccessible deposits in the polar zone has not been fully taken into account. It is necessary to develop and implement a set of measures aimed, if not to complete overcoming of objective difficulties, then at least to partially neutralize them.

\section{RESULTS AND DISCUSSION}

The work on the justification of effective geotechnologies for mining deposits in the conditions of cryolithozone based on the development of new principles for the rational development and conservation of explored reserves and predictive resources has been carried out at the Institute of Soil Science of the SB RAS for many years. Much attention is paid to improving the methods for assessing the qualitative and quantitative structure of reserves, the extent and nature of the impact of variability of the geological environment and external factors on the efficiency of development of the extraction and processing processes. Serious influence on the formation of ideas in this case was provided by Batugin $[3,17]$.

First, the authors consider a small part of the known and new, general and particular principles applicable to the innovative development of the deposits of the polar zone, synthesized from the conceptual provisions developed by the world and Russian science. The main attention will be concentrated on their use by enterprises of medium and low power. Such an accent is due to the fact that in these organizations, in comparison with large business, have limited opportunities for self-adjustment of principles in the preparation of local strategies and development programs because of organizational and financial reasons.

The general principle of nature management: maximum possible advance study of the natural environment with a high level of accounting for its features and patterns in strategic and tactical projects and actions.

Ecological and economic principle of nature management: maximum full utilization of extracted minerals. According to statistics, up to $98 \%$ of all extracted raw materials are not used, forming waste. This has an extremely negative impact on the economic efficiency of nature management, growing costs of storage and disposal of waste, reclamation of disturbed land. 
Principles of economic policy and economy of natural resources: it is important to avoid the widespread view of the homogeneity of any resource, the reserve of which is strictly determined by its volume. The analysis should proceed from a wide range of qualitative characteristics of mineral resources, which are determined primarily by the geological features of the deposits, the impact of which has not been sufficiently studied. In turn, economic and technological conditions determine which properties of the resource are most attractive for development and subsequent use [18].

Principle of systemology: dynamic stability and development of mining systems are possible only in an environment that has a certain combination of favorable and unfavorable parameters of subsystems "georesource", "technological transformation of georesource into products and potential resources", "result, product, effects of different origin" 19].

Principles of information stage of development of natural resources. The information stage of development plays a paramount role in complex studies on the problems of the development of mineral resources, unique objects and territories [20]. In its course, a deliberate accumulation of data on a set of conditions that ensure the inclusion of undeveloped subsoil blocks in operation is conducted. The principles and concepts formulated within the framework of this group are as follows: the research potential aimed at informational development of a new territory should be more proportional to their resource potential, rather than the concentration of industrial production [20]; the whole technological chain of development of new territories and subsoil plots should be linked by modern means of computerization and automation; the development of territories and subsoil, starting from the information stage, should be carried out taking into account the interdisciplinary integration of scientific forces and cooperation between industries in accordance with targeted scientific and technical programs. Now, adding a few less general but important principles of informational development of the territory and subsoil [21]: principle of analogy, which means that the methodology for studying a new territory or subsoil area is selected taking into account the studied analogous objects (in the absence of such objects or the lack of a degree of their analogy, without changes); principle of successive approximation, realized by the breakdown of the process of information development (including prospecting and evaluation of subsoil) at the stage, in each of which the study is conducted with increasing detail; principle of selective detailing, which consists in an additional study of individual sections; principle of necessary and sufficient accuracy, detail and complexity of studying the territory and subsoil as a whole. The categories of "necessary and sufficient" accuracy have practically no valid solutions to date, although research is being done in this direction. For example, there is a way to assess the level of knowledge of coal quality indicators based on the coefficient of spatial information variability and information stability [22]. With the application of methodological recommendations, a quantitative assessment of the reliability of coal deposits is carried out [23].

Principles of the stage of industrial development of natural resources: continuous improvement of the organization, requiring constant improvement of the existing management structure, its adaptation to the changing conditions of production and social relations; transition from the principle of "mineral wealth for a known technology" to "technology for extracted mineral wealth, creation of integrated quality management systems for mineral raw materials, from the field to the end user.

Principles of preparing a geo-resource for effective development, use and conservation: the need to apply scientific knowledge already at the early stages of prospecting and exploration of deposits in order for their subsequent development to be cost-saving; natural heterogeneity of the most important indicators of productive bodies, their zonality, power, properties, discontinuity cannot be established with necessary and sufficient accuracy at the 
exploration stage, their identification and correct recording in mining and processing systems of mineral raw materials are possible only on the basis of improving and implementing a representative advanced and operational testing; the need for proper use and interpretation of the results of geological testing of stocks and laboratory analysis of samples for minerals and elements to increase the reliability (for example, based on [17]).

Principles of improving and developing new effective geotechnologies, mining equipment, technological processes and operations. 1. In the mineral and raw materials sector, when choosing the directions for improving equipment and technologies, it is necessary to take into account: the growing rates of depletion of the deposits of most geotechnologically-utilized types of SM; uncertainty of their substitution with alternative scenarios; inadequate attention to fundamental research projects and forecasted areas of development of mining equipment and technologies. 2. A rational combination of two or more technologies can create a synergistic effect leading to a significant improvement in the general schemes of field development. 3. Special conditions developed in the systematic lag in the modernization and adaptation of mining equipment and geotechnologies. This is due to the continuous increase in the depth of development in the fields with associated other, also deteriorating, mining and geological conditions; forced transition to mining of deposits of another geological type or in new, as a rule, worse conditions. This principle has not been sufficiently investigated, which is manifested in mistakes in the justification of the strategies for scientific and technical policy of nature management.

Clarification of the above principles, their addition and subsequent ranking by importance for each of the development objects is planned to be performed using various foresight methods [24] (Delphi [25], scenario building, SWOT analysis, road maps), including taking into account possible options for the future development of Yakutia.

\section{CONCLUSIONS}

The reduction of risks in the implementation of investment projects for the development of fields in hard-to-reach polar regions by medium and small mining enterprises is possible with the use of the considered set of basic and particular principles.

The adoption of rational solutions in the planning, design and development of complex in terms of structure and heterogeneity in the quality of deposits should be carried out on the basis of the most accurate and reliable knowledge of the basic qualitative and quantitative characteristics of mineral raw materials in the subsoil and the technological streams formed during extraction.

The use of research results by stakeholders is important for resource-saving, economically acceptable and environmentally safe extraction and primary processing of mineral raw materials, which is competitive in the market, and allows increasing reliability and validity of solutions for the development of enterprises based on the territory of the region.

\section{References}

1. I. P. Glazyrina, S. M. Lavlinskii, I. S. Kalgina, Geography and Natural Resources, 4. (2014).

2. Status and prospects of development of public-private partnerships in the context of the complex development of mineral resources; Ed. A. E. Kontorovich, S. M. Nikitenko, E. V. Goosen (Kemerovo, Sib. Izdat. Gruppa, 2015).

3. S. A. Batugin, V. L. Yakovlev, The patterns of development of mining (Yakutsk, YSC SB RAS, 1992). 
4. G. V. Sekisov, Vestnik ZabGU, 7. (2016).

5. V. P. Orlov, Problems of Subsoil Use (2000-2006) (Moscow, Geoinformmark, 2007).

6. K. N. Trubetskoi, Yu. P. Galchenko, G. V. Kalabin, Engineering Physics, 4. (2016).

7. E. I. Zakharov, Izvestiya TulGU. Sciences of Earth, 2. (2012).

8. G. Duhaime, N. Bernard, P. Fréchette, M-A. Maillé, A. Morin, A. Caron, The Mining Industry and the Social Stakes of Development in the Arctic (Canada Research Chair in Aboriginal Comparative Condition, 2003).

9. Circumpolar Information Guide on Mining for Indigenous Peoples and Northern Communities URL: http://www.sdwg.org/wpcontent/uploads/2016/04/Circumpolar_Mining_Guide_Draft-Apr_2011.pdf (Date of access: 14.06.2018).

10. D. Avango, L. Hacquebord, U. Wråkberg, Journal of Historical Geography, 44, (2014).

11. G. V. Sekisov, N. I. Grekhnev, V. G. Romanov, N. V. Zykov, Mining Journal, 3. (2007).

12. A. I. Tonkikh, Mining informational and analytical bulletin, 11. (2009).

13. O. A. Tatarinova, Mining informational and analytical bulletin, 6. (2013).

14. D. R. Kaplunov, V. A. Yukov, Mining Journal, 11. (2015).

15. A. G. Mikhailov, Mining informational and analytical bulletin, 2. (2015).

16. I. A. Kradenykh, Mining informational and analytical bulletin, spec. iss. 21. (2016).

17. S. A. Batugin, E. D. Chernyi, Theoretical Basis of Sampling and Reserves Estimation (Novosibirsk, Nauka. Sib. predpriiatie RAN, 1998).

18. A. Endres, I. Kvener, Economics of Natural Resources ( $2^{\text {nd }}$ ed., Saint-Petersburg, Piter, 2004).

19. S. A. Batugin, S. M. Tkach, N. S. Batugina, V. L. Gavrilov, Mining informational and analytical bulletin, 9. (2012).

20. K. P. Kosmachev, V. P. Mosunov, Yu. S. Nikulnikov, A. A. Sysoev, Methodological problems of specific Sciences, 55. (1984).

21. L. I. Chetverikov, Theoretical Basis of Mineral Resources Exploration (Moscow, Nedra, 1984).

22. N. N. Grib, P. Yu. Kuznetsov, Coal (Ugol'), 9, 186 (2016).

23. T. Rogova, S. Shaklein, Reliability of the reserves of coal deposits. Quantitative assessment and monitoring (Saarbrucken, Lambert Academic Pablishing, 2011).

24. M. Conway, An Overview of Foresight Methodologies URL: http://www.forschungsnetzwerk.at/downloadpub/An-Overview-of-ForesightMethodologies1.pdf (Date of access: 19.06.2018).

25. J. Caron, S. Durand, H. Asselin, Journal of Cleaner Production, 119. (2016) 